\title{
El Atrato y sus guardianes: imaginación ecopolítica para hilar nuevos derechos
}

\author{
The Atrato River and Its Guardians: Ecopolitical Imagination \\ for Weaving New Rights
}

\author{
Diego Cagüeñas ${ }^{*}$, María Isabel Galindo Orrego ${ }^{* *}$, Sabina Rasmussen ${ }^{* * *}$ \\ Universidad Icesi, Colombia
}

DOI: $10.22380 / 2539472 X .638$

\begin{abstract}
$\overline{\text { RESUMEN }}$
La Sentencia T-622 del 2016 de la Corte Constitucional, que reconoce la cuenca del Atrato como entidad sujeto de derechos, supone una oportunidad inédita para la imaginación ecopolítica en el país. Este reconocimiento plantea retos, puesto que requiere un trabajo de traducción y representación para definir los derechos efectivos de la cuenca. Parte de este trabajo viene siendo desempeñado por el grupo de Guardianes del Atrato, quienes velan por el reconocimiento y la salvaguarda de unos derechos aún por concretar. En este artículo, abordamos la cuestión de los derechos del río no solo como un problema de representación jurídica, sino también como un ejercicio ecopolítico que busca anudar, de maneras novedosas, las vidas, las prácticas y los saberes que florecen a lo largo del Atrato.
\end{abstract}

Palabras clave: derechos bioculturales, minería, ríos, Chocó.

\begin{abstract}
$\overline{\text { ABSTRACT }}$
Judgment T-622 of 2016 of the Constitutional Court that recognizes the Atrato basin as an entity subject to rights represents an unprecedented opportunity for the ecopolitical imagination in Colombia. This recognition poses challenges as it requires translation and representation work to define the effective rights of the basin. Part of this work has been carried out by the Guardians of the Atrato who are in charge of the recognition and safeguard of rights not yet specified. In this paper, we address the issue of river rights not only as a problem of legal representation but also as an eco-political exercise that seeks to tie, in novel ways, lives, practices and knowledges that flourish throughout the Atrato.
\end{abstract}

Keywords: biocultural rights, mining, rivers, Chocó.

dcaguenas@icesi.edu.co / https://orcid.org/0000-0001-5274-5336

. Mariaisabelgalindo47@gmail.com / https://orcid.org/0000-0002-8440-9131

... sabinarasmussen@yahoo.com.ar / https://orcid.org/0000-0002-4069-4188 


\section{Imaginación ecopolítica en el Atrato}

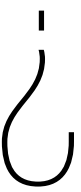

Cómo vivir y florecer en un mundo dañado? ¿Cómo hacer posible la vida en común, para humanos y no humanos por igual, a partir de un presente marcado por los incontables daños sociales y ambientales sobre los que se ha erigido el mundo contemporáneo? Este artículo, de índole reflexiva, explora un incipiente ejemplo de imaginación ecopolítica que busca ofrecer una respuesta local a estos interrogantes. Por imaginación ecopolítica entendemos aquellos ejercicios deliberados en los que una colectividad se reúne para concebir una futura casa común en donde se encuentre "recompuesta la continuidad de lo colectivo" (Latour 2007, 209). Se trata de imaginar un futuro que amplíe el espectro de lo político de modo tal que restituya y fomente las relaciones de mutua dependencia entre humanos y no humanos, tomando distancia de la usual separación entre sociedad y naturaleza ${ }^{1}$. Deseamos hacer énfasis en la idea de continuidad de lo colectivo, pues no creemos que la ecopolítica se limite a "dar directrices a favor de los componentes irrenunciables de la sustentabilidad" (Aguirre 2017, 74), ni a estimar "la posibilidad de integrar los datos de las ciencias sociales y las ciencias naturales sobre la acción recíproca de las actividades humanas y los ciclos de la naturaleza" (Guimarães 1989, 89). Lo que está en juego en la ecopolítica no es tan solo cómo hacer más armónica o "sustentable" la correlación entre acción humana y fuerzas naturales (lo cual, dicho sea de paso, suele ir aparejado a proyectos desarrollistas que ven en "la naturaleza" poco más que un acervo de "recursos" por aprovechar), sino la posibilidad de imaginar el campo político como aquel Parlamento de las Cosas (Latour 2007), en el que todas las formas de existencia comparecen bajo un principio de igualdad y continuidad.

El ejemplo de imaginación ecopolítica que abordamos aquí es consecuencia de la Sentencia T-622 del 2016 de la Corte Constitucional de Colombia que reconoce al río Atrato como sujeto de derechos. Argumentamos que esta consideración supone para las comunidades ribereñas un ejercicio de reinvención de su vínculo con el río, y, en consecuencia, de sus modos de vida, pues los ríos, como demuestra la geógrafa Kuntala Lahiri-Dutt (2019), ni están fuera de la sociedad ni son simplemente "una cosa en la naturaleza”. Por el contrario,

los ríos interactúan constantemente con la cultura, de tal manera que la forma como se tratan está ampliamente determinada por una maraña 
de relaciones y narrativas que afectan al río y con las que este está constantemente negociando e incluso resistiendo. (Lahiri-Dutt 2019, 156)

En el caso del Atrato, la sentencia de la Corte - a pesar de su lenguaje constatativo- no reconoce un estado de cosas, sino que expresa un interés; esto es, no describe una situación de facto (de hecho) sino de jure (de derecho): abre un futuro posible a través de un mandato. La sentencia busca que el río Atrato sea concebido de un modo tal que se asegure su cuidado y restauración; por tanto, la pregunta que guía nuestra reflexión es: ¿qué significa para las comunidades del Chocó en general, y para el grupo de Guardianes del Atrato en particular, tener que concebir el río como un sujeto al que se le reconocen y salvaguardan derechos aún por especificar? O, en términos de imaginación ecopolítica, ¿cómo se podría llevar al Atrato a comparecer al Parlamento de las Cosas, no ya como un fenómeno natural que ha de ser protegido por la comunidad, sino como un sujeto con voz y personalidad políticas propias, capaz de abogar por sus derechos?

Hacer del Atrato un sujeto de derechos implica contar historias nuevas, tejer relaciones inéditas e inventar prácticas que han de surgir de una relación estrecha con el carácter propio de este río. Esto supone un reto para la imaginación ecopolítica, pues requiere crear mecanismos de traducción que permitan que el comportamiento de todos los seres que conforman la cuenca del Atrato, tanto humanos como no humanos, pueda ser cobijado por la lógica jurídica que alienta la sentencia. Para tener concretos efectos locales, la ley deberá propiciar nuevas articulaciones y traducirse en prácticas de construcción de lo común que quizás aún no tengan precedentes. La ecopolítica tiene el potencial de convertir el interés de la ley en hecho social, pero esto solo puede suceder de manera local, en observancia de los modos particulares de existencia involucrados ${ }^{2}$. Así las cosas, imaginar el Atrato como sujeto de derechos demanda atender a su curso, sus fluctuaciones, sus nuevas turbiedades; implica considerar el entramado de seres vivos e inertes que prosperan y mueren en permanente interconexión a lo largo y ancho de su curso.

Nos concentraremos en un trabajo llevado a cabo en julio del 2018 en el Consejo Comunitario de la Playa (Chocó) ${ }^{3}$, junto al Centro de Estudios para la material acompañada de recursos económicos, sociales y legales, que debe proporcionar el Estado en primera instancia.

3 Los consejos comunitarios de las comunidades negras son personas jurídicas reconocidas por la Ley 70 de 1993, cuyas funciones contemplan administrar las tierras de propiedad colectiva, velar por la conservación y protección de los derechos de tal propiedad, conservar los recursos naturales y mediar en conflictos internos susceptibles de ser resueltos a través de conciliación. 
Justicia Social Tierra Digna y a los Guardianes del Atrato, en el que fuimos testigos de este naciente ejercicio de imaginación ecopolítica. Nos interesan las distintas formas, deletéreas o no, en que la sentencia puede renovar las relaciones de las comunidades ribereñas entre sí y con la cuenca del río en cuyo seno estructuran su diario vivir. Hay que anotar que nada de esto habría sido posible sin la respuesta de la Corte a una acción de tutela ${ }^{4}$ que demandaba a veintiséis entidades del Estado por no garantizar los derechos fundamentales de las comunidades ribereñas y su entorno. La tutela se estructuró con base en el derecho a la vida, a la salud, al agua, a la seguridad alimentaria, al medio ambiente sano, a la cultura y al territorio de las comunidades étnicas para solicitar medidas que solucionaran la crisis socioambiental, ecológica y humanitaria que se vive en esta cuenca, sus afluentes y territorios aledaños. El hecho de que la sentencia sea un resultado inesperado de una acción de tutela es crucial, puesto que el lenguaje de la Corte establece en buena medida los recursos conceptuales y jurídicos de los que se ha de servir la imaginación ecopolítica para darle realidad a la representación del Atrato como sujeto de derechos. A su vez, esto muestra la necesidad de tener en cuenta la profundidad histórica de un problema central de la cultura y el derecho occidentales: la naturaleza legal de ciertas entidades no humanas y la consiguiente ampliación del Parlamento de las Cosas. De modo que, antes de abordar el caso etnográfico, presentamos una corta genealogía de la sentencia, y especialmente de la noción de derechos bioculturales y la visión ecocéntrica de la naturaleza ${ }^{5}$.

4 La tutela fue presentada por Tierra Digna en representación del Foro Interétnico Solidaridad Chocó (Fisch), del Consejo Comunitario Mayor de la Organización Popular y Campesina del Alto Atrato (Cocomopoca), del Consejo Comunitario Mayor de la Asociación Campesina Integral del Atrato (Cocomacia) y de la Asociación de Consejos Comunitarios del Bajo Atrato (Asocoba).

5 “[...] los derechos que tienen las comunidades étnicas a administrar y a ejercer tutela de manera autónoma sobre sus territorios - de acuerdo con sus propias leyes, costumbres- y los recursos naturales que conforman su hábitat, en donde se desarrolla su cultura, sus tradiciones y su forma de vida con base en la especial relación que tienen con el medio ambiente y la biodiversidad" (Sentencia T-622 del 2016). 


\section{La sentencia que declara el río Atrato como sujeto de derechos}

La declaración del Atrato como sujeto de derechos es novedosa, pero no carece de antecedentes. En Latinoamérica, vale la pena mencionar la obra de Godofredo Stutzin (1984), que ya en la década de 1980 consideraba que el reconocimiento de los derechos de la naturaleza es una condición sine qua non de un auténtico derecho ecológico, contrapeso necesario frente a las concepciones instrumentalistas de la naturaleza basadas en el dominio del ser humano. A diferencia de los enfoques tecnocráticos - muchas veces parapetados tras nociones como el "interés público" o el "interés general de la sociedad"-, Stutzin reconoce que la naturaleza tiene intereses propios. Otro antecedente importante es el concepto de constitución ecológica desarrollado por la Corte Constitucional de Colombia desde su Sentencia T-411 de 1992, con el cual la Constitución incorpora el derecho constitucional fundamental al ambiente como un eje vertebral de los derechos consagrados allí. Por su parte, la Sentencia C-519 de 1994 declaró exequible el Convenio sobre Diversidad Biológica de 1992. Allí la Corte sienta las condiciones de protección del derecho fundamental al ambiente y su relación con los derechos a la vida, la integridad y la salud ${ }^{6}$.

Ahora bien, en el caso que nos compete, ¿qué significa la medida jurídica de la Corte? Si estamos hablando de una tutela, ¿esta no debería salvaguardar los derechos humanos en lugar de otorgarle derechos a un ente no humano ${ }^{7}$ ? A este respecto vemos cómo la Corte se asoció con el enfoque ecocéntrico de la

6 Macpherson y Clavijo (2018) muestran cómo la Corte retoma la jurisprudencia sobre los derechos ambientales de indígenas y afrodescendientes, y se apoya en la constitución ecológica, la noción de vida digna, el bienestar general y la justicia social, conceptos que fundamentan el Estado social de derecho. Retoma además la jurisprudencia de la Corte Interamericana de Derechos Humanos, la Convención 169 de la Organización Internacional del Trabajo, la Declaración de Naciones Unidas sobre los Derechos de los Pueblos Indígenas, la Convención de Biodiversidad, la Declaración Americana de los Derechos de los Pueblos Indígenas, la Convención para la Salvaguardia del Patrimonio Cultural Inmaterial de la Organización de las Naciones Unidas para la Educación, la Ciencia y la Cultura (Unesco) y el derecho humano al agua, y analiza casos internacionales en los que incluye el del río Whanganui en Nueva Zelanda y los derechos de la naturaleza en las constituciones de Ecuador y Bolivia. Sobre estas discusiones, el trabajo de Eduardo Gudynas (2014) es de especial relevancia.

7 En principio, la sentencia buscaba responder a una tutela que pedía: “detener el uso intensivo y a gran escala de diversos métodos de extracción minera y de explotación forestal ilegales, que incluyen maquinaria pesada — dragas y retroexcavadoras - y sustancias altamente tóxicas -como el mercurio- en el río Atrato (Chocó), sus cuencas, ciénagas, humedales y afluentes, que se han venido intensificando desde hace varios años y que están teniendo consecuencias nocivas e irreversibles en el medio ambiente, afectando con ello los derechos fundamentales de las comunidades étnicas y el equilibrio natural de los territorios que habitan" (Sentencia T-622 del 2016). 
naturaleza, según el cual el ser humano es una especie entre las demás, sin atribuciones de dominio ni propiedad sobre estas. Según este enfoque, lo que Occidente ha denominado naturaleza tiene derechos propios que deben ser reconocidos y protegidos, así como los de las comunidades humanas relacionadas con ella ${ }^{8}$.

Dos asuntos de la sentencia llaman especialmente nuestra atención. Primero, el desarrollo de los derechos bioculturales que contemplan la relación de ineluctable interdependencia entre naturaleza y cultura, es decir, entre comunidades étnicas y territorio. Estos derechos surgen del "reconocimiento de la profunda e intrínseca conexión que existe entre la naturaleza, sus recursos y la cultura de las comunidades étnicas e indígenas que los habitan, los cuales son interdependientes entre sí y no pueden comprenderse aisladamente" (Sentencia T-622 del 2016) ${ }^{9}$. Según esta lógica relacional, se entiende que la defensa y protección de las comunidades está unida a la del territorio y sus características biofísicas. No se puede garantizar los derechos de las comunidades del Atrato sin tener en cuenta la cuenca y sus habitantes en su integralidad. El enfoque relacional e interdependiente de los derechos bioculturales, tan familiar para muchas comunidades del mundo, se presenta como un quiebre y una novedad en la cosmovisión moderna occidental que empieza a tratar de incorporarlo lentamente y no sin dificultades.

El segundo asunto tiene que ver con la declaración de la Corte Constitucional, en la Sentencia T-622 del 2016, según la cual "la justicia con la naturaleza debe ser aplicada más allá del escenario humano y debe permitir que la naturaleza pueda ser sujeto de derechos", y la consecuente decisión de "dar un paso adelante en la jurisprudencia hacia la protección constitucional de una de nuestras fuentes de biodiversidad más importantes: el río Atrato”. Al poner los derechos bioculturales en una perspectiva ecocéntrica, la Corte da un salto cualitativo al declarar que "el río Atrato es sujeto de derechos que implican su protección, conservación, mantenimiento y en el caso concreto, restauración”.

[...] "la tierra no pertenece al hombre y, por el contrario, asume que el hombre es quien pertenece a la tierra, como cualquier otra especie. De acuerdo con esta interpretación, la especie humana es solo un evento más dentro de una larga cadena evolutiva que ha perdurado por miles de millones de años y por tanto de ninguna manera es la dueña de las demás especies, de la biodiversidad ni de los recursos naturales como tampoco del destino del planeta. En consecuencia, esta teoría concibe a la naturaleza como un auténtico sujeto de derechos que deben ser reconocidos por los estados y ejercidos bajo la tutela de sus representantes legales, verbigracia, por las comunidades que la habitan o que tienen una especial relación con ella" (Sentencia T-622 del 2016). problemática y restrictiva, pues supone que existen comunidades "más cercanas" a la naturaleza en virtud de sus reivindicaciones identitarias. Para el caso del Pacífico colombiano, véase Wade (2006). 
Finalmente, deseamos resaltar que la decisión de la Corte se apoya en la convicción de que las medidas adoptadas por el Estado colombiano se han caracterizado por su enfoque asistencialista y desarticulado, lo que ha dificultado la protección eficaz de la cuenca ${ }^{10}$. Así, es posible ver cómo la sentencia hace énfasis en la interconexión de los distintos derechos que requieren protección estatal, pues todos ellos dependen del río. La apuesta es, por ende, la declaración de un nuevo sujeto no humano de derechos que posibilita el cumplimiento de los derechos de los humanos cuyas vidas dependen de él. Pero, como mencionamos, tal sujeto no humano de derechos es una creación jurídica de la Corte, de modo que su tránsito hacia una existencia de hecho en el territorio es una tarea que también recae en las comunidades a las que la sentencia delega la tutela del río.

Aunque no es nuestro propósito ahondar aquí en las profundas implicaciones jurídicas de la medida, hay que señalar el desafío que representa que este nuevo sujeto de derechos sea representado legalmente, obligación que la Corte delega en un miembro de las comunidades accionantes y un delegado del Estado colombiano. Es en respuesta a esta necesidad de representación que se conforma el grupo de Guardianes del Atrato. De esta manera, la sentencia no solo hace del río un sujeto de derechos, sino que también da pie a la creación de una suerte de sujeto colectivo conformado por la gente del río que, sin haberlo previsto, se enfrenta a la tarea inédita en el país de volver concretos los derechos declarados por la sentencia, además de propender por su defensa y cumplimiento. Es justo en esta apertura donde se encuentra el ejercicio de imaginación ecopolítica que analizamos aquí.

La forma en que se concreten y se traduzcan esos derechos apenas esbozados es una de las claves para que la sentencia no sea solo un compilado de buenas intenciones. Se trata, como dijimos, de hacer un ejercicio de traducción entre lo que enuncia la sentencia y lo que la gente del río requiere para vivir y florecer en una cuenca dañada. Es así como el lenguaje de los derechos se instala en el corazón mismo de una imaginación ecopolítica que ya no puede permitirse ver en el río tan solo un objeto inerte, un "fenómeno natural" o un "recurso" que debe ser aprovechado y controlado (Lahiri-Dutt 2019).

10 Por ejemplo, se declaró la responsabilidad por omisión de las entidades demandadas en la vulneración del derecho a la seguridad alimentaria de las comunidades y el derecho fundamental al agua, por la contaminación de las fuentes hídricas y los bosques. Esta contaminación afecta las formas tradicionales de producción de alimentos, así como su disponibilidad. 
Figura 1. Cuenca del río Atrato, 2018

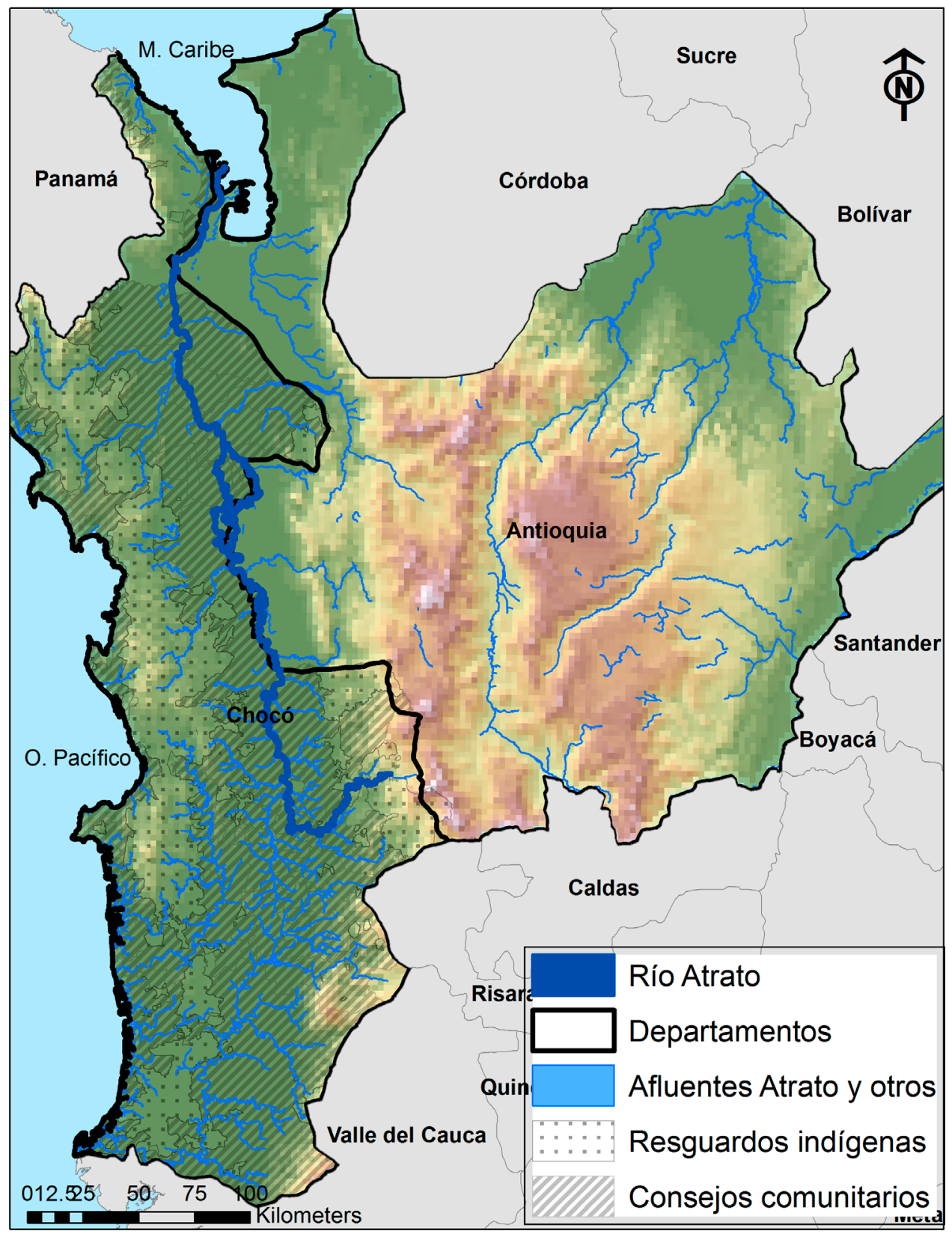

Fuente: mapa elaborado por Juan Pablo Milanese. 


\section{Los Guardianes del Atrato}

La Sentencia T-622 del 2016 establece que la representación del río debe estar a cargo de dos guardianes, uno del Estado, designado por el Ministerio de Ambiente, y otro de las comunidades. Los representantes de estas últimas hicieron su propia interpretación y decidieron que un guardián no basta: "nosotros fuimos más allá de lo que dijo la Corte”, expresaba uno de los guardianes durante una entrevista en Quibdó en julio del 2018. ¿Quién podría “hablar” por el Atrato y hacer el ejercicio de traducción de las necesidades del río y sus gentes? ¿Cómo pensarlo como un sujeto? ¿Cómo hacer seguimiento a la sentencia? Lo primero que señalaron es que "un guardián no hubiera conocido todo el río". El río que nace en el Carmen del Atrato no es el mismo que desemboca en el golfo de Urabá. El hilo del río va tejiendo muchas tramas, va cambiando, así como va variando la gente que habita su cuenca.

Como se evidenció en el taller en el que participamos, y que describiremos enseguida, cada uno de los guardianes y guardianas ${ }^{11}$ tiene "su" río: el cristalino, bravo e impredecible del nacimiento, hasta el lodoso, lento y radicular de la desembocadura. Las comunidades afros, indígenas y campesinas imaginan cada una un río diferente. El que baña el malecón del Quibdó y el que trae el bocachico en Puné; el que deja oro en las orillas de Yuto y el que une a Bellavista, en el Chocó, con Vigía del Fuerte, en Antioquia; el que surcan las pangas (pequeñas embarcaciones de madera) con el mercado y las embarcaciones de los grupos armados. Esta diversidad llevó a que a las organizaciones que originalmente interpusieron la acción de tutela con el apoyo de Tierra Digna se unieran en los Consejos Comunitarios del Río Quito, la Mesa Socioambiental del Carmen del Atrato y la Mesa Indígena del Chocó. Como afirmó uno de los guardianes, "no se trata solo de planes de acción, se tiene que articular con los accionantes, entre las organizaciones". En ese sentido, se entendió la sentencia como una oportunidad de establecer una conversación que, sin desconocer las diferencias, reuniera -en algunos casos por primera vez-, la multitud de comunidades ribereñas para imaginar colectivamente la cuenca del Atrato.

11 En el taller participaron Aníbal Córdoba, del Medio Atrato; John Palacio, de San Isidro; Bernardino Mosquera, de Paimadó (río Quito); Milton Piedrahita, del Bajo Atrato; Marjury Mosquera y Delbys Copete, de Cocomopoca; Alexander Rodríguez, de Cocomacia, y Claudia Domicó, del Resguardo Indígena de Bejeró. También estuvieron presentes un integrante de la Diócesis de Quibdó y habitantes del Consejo Comunitario de La Playa (municipio de Lloró). En Quibdó conversamos con Nixon Chamorro de la Mesa Departamental Indígena. En la Universidad Icesi contamos con la visita de Valerio Andrade de Paimadó e Ingris Asprilla de Tagachí, en un evento realizado por la Facultad de Derecho y Ciencias Sociales acerca de la Sentencia T-622 en marzo del 2018. 
Uno de los primeros frutos de esta conversación fue la decisión de que todas las comunidades tengan una representación doble: un hombre y una mujer, ya que cada género sostiene una relación particular y distinta con el río.

\section{Taller sobre los derechos del río con los Guardianes del Atrato}

Las aguas del río Capá, aún claras y despojándose del frío del páramo, corren, por un par de minutos, frente al Consejo Comunitario de La Playa, en el municipio de Lloró. El caserío está ubicado en un recodo que forma el Capá antes de desembocar en el Atrato, aguas arriba de Quibdó. Para llegar allí recorrimos por tierra un trecho de la carretera que comunica a Quibdó con el interior del país y que nos condujo a la cabecera municipal de Lloró. En la confluencia del río Andágueda y el Atrato nos embarcamos Atrato arriba hasta llegar a las bocas del Capá, cuyas aguas nos llevarían - subiendo contra la corriente- a La Playa. Nuestra llegada estuvo acompañada, como lo estaría cada tarde, por la lluvia persistente de la selva chocoana. Allí hicimos parte de un encuentro entre integrantes del grupo de Guardianes del Atrato, de Tierra Digna y de la Universidad Icesi, cuyo objeto era comenzar a imaginar cuáles son los derechos que le pertenecen a la cuenca, mediante una serie de actividades destinadas a comprender qué significa que el río sea sujeto de derechos. Se trató de un taller inicial, que buscaba comenzar a darles cuerpo a los derechos de la cuenca. En esa medida, los argumentos que presentamos aquí son también iniciales y tienen la intención de servir más como provocaciones para ampliar y enriquecer el debate, que como un balance de los efectos de la sentencia (algo de todos modos muy difícil debido a lo reciente que es) ${ }^{12}$.

Le pedimos a cada participante, llegado desde distintos afluentes del Atrato, que trajera agua de su río en una botella. Al describir el contenido esperábamos que se hiciera evidente no solo que las aguas cambian a medida que se acercan al océano, sino que cada guardián describiera su relación con las aguas del río de modo particular (luego, hicimos un recorrido durante el que

12 Al taller fuimos invitados por Tierra Digna, luego de que presentaran en Icesi su trabajo junto al grupo de Guardianes y compartiéramos con ellos nuestra investigación en los ríos Pance y Quito. Las entrevistas se llevaron a cabo durante el taller en La Playa, en Quibdó y en Cali, gracias a la visita de dos representantes de los Guardianes a la Universidad. El equipo de Icesi estuvo integrado por dos antropólogos, una politóloga y una abogada. 
recogimos objetos que enferman el cauce y el lecho). Ello, a su vez, abriría la conversación acerca de los daños precisos que el río ha sufrido y que, por tanto, habrían de guiar las iniciativas de conservación, protección, restauración y mantenimiento que estipula la sentencia. Los resultados de este encuentro dibujaron el horizonte sobre el cual reflexionamos en este artículo.

La primera parte del taller rastreó el origen ribereño de los participantes y las perspectivas que los distintos afluentes revelan sobre la vida en el Atrato. A través del agua de su respectivo río, cada guardián compartió lo que dicha sustancia comunica, tanto en su materialidad como en las historias que suscita: cómo es y cómo era el río, qué tan dañado está, qué actividades tienen lugar en su cauce, cómo se ha transformado la vida en y con el río. Partimos de la idea de que la gente entabla cotidianamente un diálogo con el río a través de sus quehaceres diarios. Este ejercicio permitió escuchar al río, empezar a reconocer cómo se comunica e identificar que existen varios ríos, cada uno con diversas facetas.

La segunda actividad consistió en la elaboración de un collage con materiales recogidos en la orilla del río. Las preguntas que guiaron este momento fueron: ¿dónde recogimos ese material?, ¿de dónde viene?, ¿cómo llegó al río?, ¿qué le hace al río?, ¿qué relación tenemos con ese material? Como en el ejercicio anterior, este fue un momento de escuchar al río para luego ser sus portavoces. A través de su materialidad y de los relatos que cuentan los objetos recogidos, se buscaba explicitar las diferentes formas de comunicación que las comunidades tienen con el río, poniendo el acento en su forma de "decir" cosas y de hacerse oír.

Un tercer momento del encuentro estuvo destinado a reconstruir, desde la perspectiva del grupo de Guardianes, la "personalidad” del río. La pista para pensar en esto fue la inquietud sobre qué distingue al Atrato de otros ríos. El propósito era identificar la forma de ser del Atrato, su identidad o personalidad, y hacer énfasis en lo que dice el río, cómo lo dice y a quién se lo dice. Luego nos concentramos en el papel del guardián como mensajero del río, mediante un ejercicio de rastreo de síntomas que revelarían las "enfermedades” del Atrato, con el objeto de comenzar a imaginar posibilidades de sanarlo.

Por último, indagamos acerca de lo que los atrateños entienden por la expresión derechos del río. ¿Qué necesita el río para vivir?, ¿qué se necesita hacer para proteger la identidad/personalidad del río?, ¿cómo sanarlo? Estos interrogantes buscaban comenzar a llenar de contenido lo que plantea la sentencia y traducir en términos propios del saber local su lenguaje jurídico. Se exhortó a pensar en los deberes de la gente con el río para identificar las mutuas implicaciones de la relación entre este mundo ribereño y las poblaciones humanas que con él se han coproducido. Ello nos permitió reflexionar sobre el sentido de 
Figura 2. Collage con materiales rescatados del río Capá

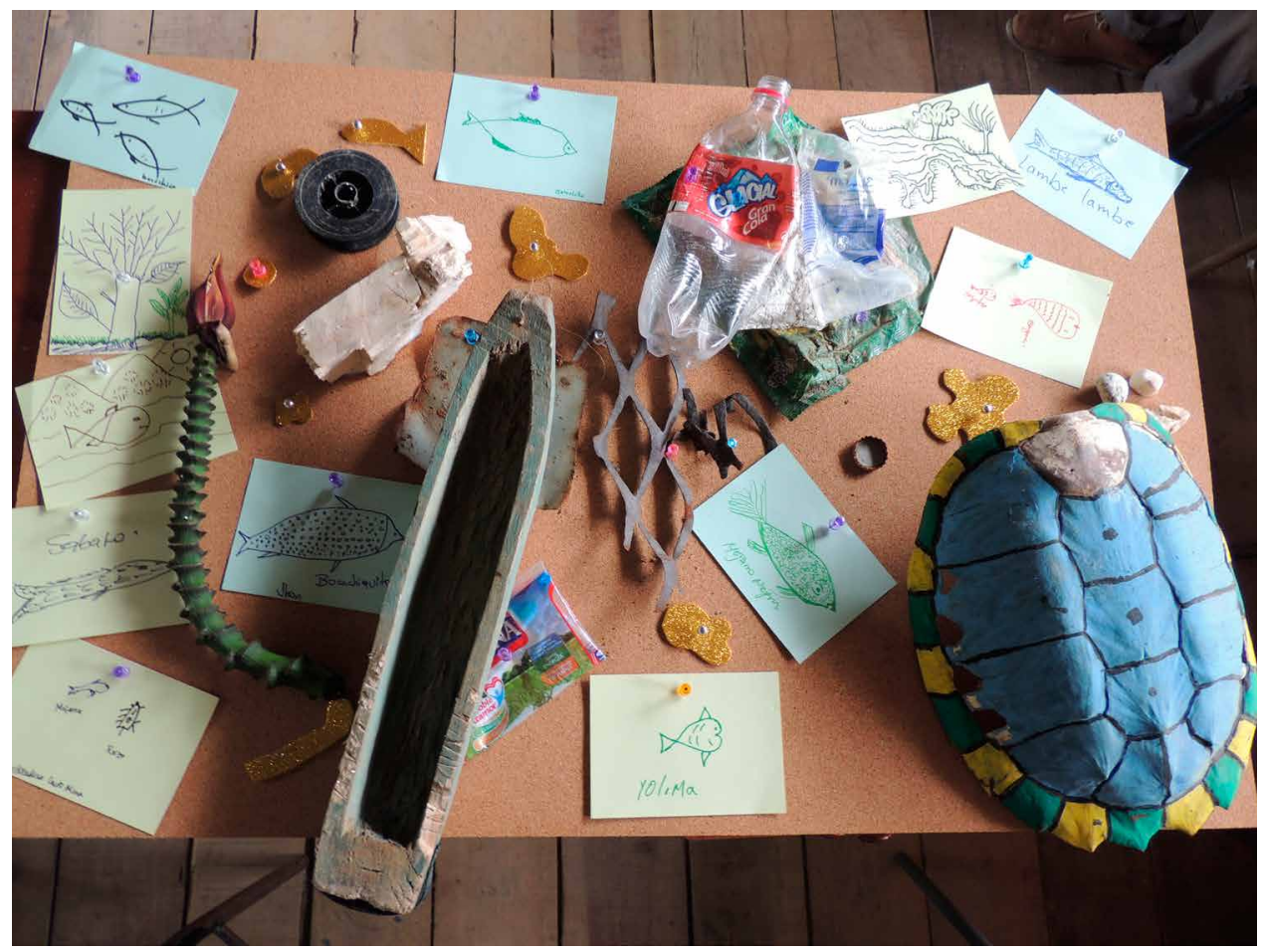

Fuente: fotografía de Sabina Rasmussen.

proteger, conservar, mantener y restaurar la cuenca del Atrato, tal como propone la sentencia, pero desde la mirada de los guardianes y de las comunidades que representan. A continuación, presentamos algunas reflexiones derivadas de este taller.

\section{Sobre las aguas del Atrato: aguasucia y vida orillera}

Las aguas que corren por el Atrato llevan consigo la historia del Chocó. Una historia profundamente atravesada por un modo de producción cuyos procesos de explotación y extracción, cuyas lógicas de fabricación y acumulación, cuyas políticas de distribución y desregulación se inscriben -en nombre del desarrollo y el bienestar- en las fuerzas geomorfológicas que dan forma al hábitat de la totalidad de seres (vivos, no vivos, humanos y no humanos) que conforman la cuenca 
atrateña. El modo de producción capitalista que nos atañe, con su promesa de liberar al ser humano de la coerción de la naturaleza, desembocó en un fenómeno paradójico: ha convertido a la humanidad en fuerza geológica, formadora y destructora de mundos y, por tanto, la ha injertado de manera ineludible en los mismos procesos naturales de los que soñaba liberarse (Chakrabarty 2009, 207-212).

Que las aguas que corren por el Atrato lleven consigo la historia del Chocó quiere decir al menos dos cosas. Primero, teniendo en cuenta los orígenes en gran medida antropogénicos del calentamiento planetario, de la acelerada extinción de múltiples especies y de la creciente desigualdad socioeconómica en las economías nacionales y mundiales, se ha de cuestionar la distinción entre historia natural e historia humana heredada del humanismo, para dar paso a una narrativa en la que rocas, ríos, mares, vientos y formas vivas de todo tipo aparezcan como registros en los que se inscribe el impacto ecopolítico de las fuerzas humanas y no humanas que distribuyen vida y muerte a lo largo y ancho de la Tierra (Szerszynski 2012, 181). En esto consiste la ampliación del Parlamento de las Cosas. Segundo, se hace indispensable reconocer que la transformación del ser humano en agente geológico implica "ampliar [scale up] nuestra imaginación de lo humano"13 (Chakrabarty 2009, 206), para dar pie a una historia en la que "devenido animal en común, el individuo pensante, múltiplemente asociado, se transforma en piedra” (Serres 2004, 38). O en río. O, mejor, en guardián del río.

El aguasucia es protagonista fundamental de la historia fluvial que antecede a la sentencia y el recurso de los atrateños al sistema judicial colombiano en busca de proteger su mundo y sus formas de vida. La cuenca del Atrato, como gran parte del Pacífico colombiano, es una tierra de agua. Los numerosos ríos que la conforman conectan asentamientos humanos y permiten el movimiento de múltiples formas de vida, urdiendo así una cuenca, un espacio acuático en el que fenómenos acuosos, como abundantes precipitaciones, enérgicas mareas, intrincadas redes fluviales, pantanos, manglares e inundaciones cíclicas, moldean los hábitos de quienes en él moran (Oslender 2002, 92).

Milton, originario de Riosucio, un municipio chocoano de la zona del Darién, no pudo traer la botella con agua de su río, pero nos pidió imaginarla. Allí, contó, el agua es tan turbia que "parece un chocolate”. Con sus manos batía el chocolate imaginario para ayudarnos a entender la dimensión del problema. Ya que algunos guardianes se habían referido al nacimiento del Atrato como a un "manantial de aguas azules", el contraste que Milton planteaba resumía en un simple gesto la acumulación de daños que el río ha recogido cuando llega a su orilla. Si

Las traducciones son propias. 
bien esta turbiedad no necesariamente es sinónimo de daño, ya que puede deberse a sedimentos, taninos, vegetación, la superficie del lecho o características de la corriente, cuando Milton comparaba las aguas del río de hoy con las del de ayer, comenzaba a emerger un compendio fluvial de relaciones materiales que dejan su traza en el agua y las vidas que de ella beben. La sedimentación, la esclavitud, la deforestación, la minería, la erosión, el mercurio, la pobreza, el conflicto armado... todo ello se decanta a través de temporalidades, escalas y efectos disímiles, debidos a las causas propias de cada uno de estos fenómenos, en la turbiedad de chocolate de las aguas en Riosucio, topónimo cuya cruel ironía no se puede ignorar.

No era nuestro primer encuentro con esta forma de turbiedad. Ya habíamos oído hablar del aguasucia en una reunión previa con una de las comunidades ribereñas del río Quito, también afluente del Atrato, y uno de los más dañados por la avanzada de la minería mecanizada de gran porte en el Chocó. Las marcas de esta clase de minería en el territorio se dejan ver a pocos kilómetros de Quibdó: riberas desnudas de vegetación, montañas de piedra, retroexcavadoras horadando el lecho del río, campamentos mineros temporales de plástico negro y polisombra verde, dragas que nos advirtieron no fotografiar, maquinaria abandonada. El cauce del río se ensancha por la acción de las dragas, a tal punto que la sedimentación producida por el volteamiento de las orillas hace imposible la navegación en épocas de poca lluvia. Durante la reunión, una de las señoras de más edad hacía hincapié en un tema: "tenemos problemas desde que llegó el aguasucia”, "nos estamos enfermando con el aguasucia”. No se trata simplemente de que el río esté sucio o contaminado, sino de que hay algo nuevo que viene a cambiar las relaciones con las aguas: el aguasucia es un agente engendrado por la diversidad de fuerzas humanas y no humanas que conforman la cuenca, como la minería de gran porte, la tala indiscriminada o la falta de tratamiento de residuos. Cuando retornábamos a los botes, un grupo de niños y niñas jugaba en el agua, ajenos a las angustias de los mayores, hasta que se escuchó la voz de una mujer gritándoles “isalgan de ahí que esa es el aguasucia!”.

Cómo se convirtieron partes del río en aguasucia es una historia larga y compleja. Uno de los elementos decisorios en esta transformación es el cambio en las formas de hacer minería de oro en la región con la entrada de maquinaria de gran porte ${ }^{14}$. Las máquinas (retroexcavadoras, dragas, dragones) y algunas sustancias tóxicas, en especial mercurio, empezaron a llegar alrededor de la década de 1990, y alcanzaron su pico a comienzos del presente siglo. Esto marca 
una diferencia de fondo con las prácticas mineras tradicionales. Los años 2007 y 2008 constituyen el momento en que la presencia de las máquinas "explota” y se multiplica en la zona del río Quito. Este quiebre se relaciona con múltiples factores, como el control territorial ejercido por grupos armados de diferente talante que convierten la región - considerada un "remanso de paz" hasta la década de 1980 - en un escenario de disputa de la guerra. Los grupos armados luchan por apropiarse de rentas ilegales de la minería, dinamizando y controlando la explotación minera, frecuentemente recurriendo a la fuerza (Valencia y Rasmussen 2018).

Los actores implicados en la extracción minera de gran porte suelen ser foráneos. De hecho, es común encontrar referencias a los brasileros y a los paisas ${ }^{15}$ como aquellos que llegaron con las máquinas a la cuenca del Atrato. A esto se suman factores como la subida del precio del oro y la liberalización de su mercado, la posibilidad de incorporarlo al circuito legal por no ser un producto ilícito, la incapacidad y falta de voluntad de los sucesivos gobiernos por controlarlo, y el persistente círculo de pobreza en el que se encuentra la población local, a pesar de habitar una zona reconocida por su riqueza en recursos naturales, continuamente explotados en sucesivos ciclos extractivistas. Sin pretender afirmar que la minería mecanizada de gran porte es la única responsable de la aparición del aguasucia, sí creemos que en las últimas décadas se ha convertido en el principal generador de turbiedad en las relaciones ecopolíticas en la cuenca del Atrato. Que esto se haya dado en un lapso tan breve habla de la intensidad del daño causado: en la mayoría de ríos chocoanos, ahora turbios, se ve entorpecido el florecimiento de la vida orillera.

El de vida orillera es un concepto local de gran importancia para el ejercicio de determinación de derechos de la cuenca. "El río nos prestó sus orillas para que viviéramos en ellas", sostiene Milton, quien se declara un experimentado pescador del Bajo Atrato y ve en el río "un maestro de vida”. Como él, algunos de los guardianes defienden que la vida de la gente ribereña está amarrada a la del río Atrato y sus afluentes. Recuerdan que sus padres y abuelos "venían agua abajo buscando fortuna”. Después de que los asentamientos mineros ubicados en las cabeceras de los ríos se difuminaron en nuevas formas de poblamiento, especialmente luego de la abolición de la esclavitud hacia la mitad del siglo XIX, quienes se dedicaban a la actividad aurífera colonial se establecieron en

15 Paisa es la denominación que se usa en el Pacífico para identificar a quien no es "negro" ni "indio", y que normalmente ha nacido en el interior del país. Vale la pena recordar la importante presencia antioqueña en el Chocó. Incluso en algunas zonas el río Atrato traza el límite entre ambos departamentos y sus bocas se abren al golfo de Urabá, que es a la vez chocoano y antioqueño. 
los cursos medios y bajos de los ríos (Leal 2016). Las orillas dibujaron entonces un nuevo horizonte para la vida y perfilaron las singulares formas de habitar de aquellos que se dicen orilleros. Antes de eso, sin embargo, pueblos indígenas y negros libertos conocían ya esas orillas. Cuenta Claudia, una mujer embera nacida en Carmen de Atrato, que en el tiempo remoto en que apenas empezaba a nombrarse el mundo, los ríos brotaron en el lenguaje según la abundancia que los caracterizaba. El Andágueda, por ejemplo, era "el río de las mariposas”. El Atrato, por su inmensidad, fue llamado "el río grande"16.

Algunas aproximaciones desde los estudios sociales han exaltado la importancia de los ríos en la configuración de territorialidades en el Pacífico colombiano. Las arterias fluviales y la extracción de oro constituyen los ejes a través de los cuales se impulsó el poblamiento de las tierras bajas (Aprile-Gniset 1993; West 2000). Anne Marie Losonczy (2006) explica que en un primer ciclo de asentamientos dispersos, la pesca, la minería y los cultivos obligaban al desplazamiento ribereño y servían como excusa para el encuentro con gentes de otros ríos. Así, el parentesco y los patrones de poblamiento se articularon con "los dos núcleos formadores de este universo, el oro y el viaje”. Este último, en especial, encarna un deseo de movilidad que emerge como "contrapunto de la esclavitud” y se fortalece gracias a las características ecológicas de la región (Losonczy 2006, 105). El espacio acuático devino protagonista en tanto que el río constituyó la ruta del poblamiento humano siendo "el recurso material para los asentamientos y el contexto físico para la interacción social” (Oslender 2008, 187).

La vida orillera depende de la pesca, de los cultivos de plátano, arroz y piña, de la madera y de minear con la batea ${ }^{17}$. Ser orillero es conocer el río, no temerle, bañar en sus aguas desde los primeros años y cruzarlo a nado sin pelear con la corriente. Ser orillero es bañar en la lluvia y jugar fútbol descalzo sobre la tierra desnuda bajo el aguacero. Es también pescar en la tormenta tentando la furia de relámpagos y truenos. Los orilleros saben leer las señales que el río susurra a través de los cambios en su forma y en su carácter: "uno aprende a conocer sus mensajes", dice Claudia, "el viento es un mensajero y el olor también indica cuándo crece, y cuándo trae o no pescado”. El río se manifiesta cuando inunda y cuando seca, cuando llueve en las cabeceras y baja embravecido arrastrando

Sobre el incierto origen del nombre Atrato, véase Isacsson (1975).

Esta forma de minería ha sido desplazada por la expansión de la actividad minera mecanizada de gran porte. Hoy en día, quienes barequean dependen de las pocas horas en que las máquinas conceden la posibilidad de mazamorrear en un paisaje ya removido por las retros. Sin embargo, en el río Capá, algunas mujeres siguen yendo con sus bateas a buscar oro. En este afluente del Atrato la minería mecanizada no ha hecho tantos estragos como en el río Quito. 
animales, personas y casas. El río habla su propio lenguaje y no todos pueden descifrarlo: "la expresión del río es algo que uno vive”, explica Nixon, guardián representante de la Mesa Indígena. Se trata entonces de un entendimiento forjado en la experiencia y la memoria.

Pensando en la manera en que el río y sus orilleros se configuran mutuamente, Ulrich Oslender exalta la relación entre el espacio acuático propio de la geografía del Pacífico colombiano y los procesos organizativos de los consejos comunitarios de las comunidades negras. Defiende, en ese sentido, que el carácter fluido y en movimiento del entorno litoral cimienta las dinámicas de las luchas políticas de los pueblos cuya historia sucede al compás de los cauces ribereños, y reconstruye una trama en la que entorno y subjetividad se amarran para dar lugar a identidades y epistemologías acuáticas, es decir, formas de conocimiento local cuya referencia fundamental es el río (Oslender 2008).

Si atendemos a esta conexión entre río, vida y movimiento, nos acercamos a la articulación de modos de vida y territorialidades que "configuran comunidades, pueblos y familias, pero también movimientos sociales, formas de resistencia y alternativas para hacer política” (Quiceno 2016, 7). Esto ayuda a comprender por qué la irrupción de la guerra, encarnada en la presencia de los armados, rompe la movilidad y el flujo constantes, propios del proceso vital de los chocoanos. Aquí emerge la oportunidad de pensar la sentencia y especialmente la labor del grupo de Guardianes, en el marco de un mundo en movimiento cuyo interminable fluir se ve amenazado, no solo por la guerra sino también por las rupturas ecológicas y sociales que conlleva la minería mecanizada de gran porte.

El cierre del río al que alude Natalia Quiceno (2016), además de haber sido suscitado por el confinamiento al que obliga la presencia de los grupos armados, es resultado de la irrupción de actores externos que desde la década de 1990 "inundaron el río de dragas", de acuerdo con Valerio, originario de Paimadó. El cierre del río ha resultado en la limitación de las actividades domésticas, la sedimentación que impide navegar, la erosión del terreno que acaba con las zonas de cultivo en sus orillas - hoy convertidas en volcanes de arena-, el cambio de los cauces que mutan radicalmente el paisaje ribereño y la ruptura de las relaciones sociales y los vínculos familiares. Para apropiarse de nuevo de su río, los afroatrateños "se embarcaron para resistir y recuperar el movimiento" (Quiceno 2016, 79). Esto, según Ingris Asprilla, guardiana originaria de Tagachí, supone sanar el río, recomponiendo los vínculos que lo amarran a las comunidades que moran en sus orillas. 


\section{El hilo del río}

"El río tiene hilo", afirman los guardianes. Cuentan que sus viejos curaban con el Atrato mediante aquel hilo del que brotaba un agua limpia y sanadora. El hilo señala el ímpetu del cauce y por él viajan los elementos que la fuerza del agua arrastra: los árboles arrancados a la selva, la maleza que se revuelve con la lluvia, el plástico y los restos de la fiebre minera. En la maraña que forma este universo fluvial, el hilo zurce una trama que amarra el mundo acuático con aquel que se despliega en sus orillas ${ }^{18}$. El Atrato es lugar de encuentros: varios acentos y lenguas comunican distintos orígenes de la gente, y la diversidad en las artes de pesca, por ejemplo, revela las diferentes formas de entenderse con este mundo hecho de agua ${ }^{19}$. Los pueblos orilleros son muchos. Pueblos indígenas, comunidades afros y mestizos campesinos, además de los numerosos paisas que han llegado de otras zonas del país, habitan esta cuenca. Las múltiples formas del río y de sus gentes son bien conocidas por los atrateños. Casi helado y cristalino en su nacimiento, se encajona luego entre piedras gigantescas y viaja veloz hasta su cauce medio, donde empieza a ser navegable. En su parte alta el Atrato es visto con respeto, dicen los guardianes, "allí no acepta nada, ni siquiera la pesca, y a ese animal bravo hay que dejarlo quietecito”. El Medio Atrato es rápido y profundo, muy poblado en sus orillas y testigo como ninguno del reciente avance minero y del crecimiento de Quibdó. En su parte baja aparece inmenso, nutrido con el agua de todos sus tributarios; es lento y fértil, surcado por suelos inundables. Saber todo esto es ser gente de río. Cuenta Nixon que en su comunidad los niños llegan al mundo dentro del agua. En esos lugares, mientras se entierran la placenta y el cordón umbilical después del alumbramiento, los parientes "se bañan en el río para limpiar y quitarle la pereza al recién nacido”. Las quinceañeras

Otros tejidos, tramas y marañas hilan el mundo pacífico. Emilia Eneyda Valencia, de la Asociación de Mujeres Afrocolombianas, explica que las trenzas de las mujeres afrocolombianas esclavizadas dibujaban el camino hacia la libertad y en ellas se escondían algunas semillas prohibidas que luego eran sembradas. Nancy Motta (2005) piensa el entorno litoral como un tejido viviente en el que interactúan flujos naturales y culturales. María Isabel Galindo (2018) propone pensar una trama telúrica que liga la humanidad al perfil y las conmociones de la tierra en una localidad del Pacífico vallecaucano cuyos habitantes conviven con el empuje de la marea.

Una anécdota ilustra esa diversidad: una tarde de aguacero, como casi todas, mientras volvíamos a La Playa luego de visitar un caserío cercano, paramos a pescar. Bajo una lluvia que penetraba la piel y aturdidos por una tormenta que hacía temblar la lancha hecha de metal, los atrateños intentaban ponerse de acuerdo sobre la mejor forma de lanzar la red. Estaban acostumbrados a distintas mallas y diferentes maneras de extenderlas sobre el viento y el agua, tanto así que el tiempo se nos pasó procurando coordinar una coreografía de pescadores variopintos que resultó más en risas que en abundante pesca. 
también entran al río como parte del tránsito que las convierte en mujeres. El Atrato, sostienen los guardianes, es la madre y el padre de los pueblos orilleros.

Pero ahora "el río está muy enfermo", afirman. La subienda, que "era una fiesta y era la vida para los hijos del Atrato”, se acabó. Recuerda Milton que antes podían pescarse cien o doscientos bocachicos en Riosucio. Hoy en día lentear ${ }^{20}$ es casi imposible porque el agua permanece turbia. El agua del Quito, antes cristalina, hoy "solo sirve para vaciar el baño", se lamenta Jhon, nacido en San Isidro. Las ciénagas de Puné, abajo de Quibdó, surtían de bocachico el resto del río. Según Aníbal, originario de ese poblado, "el pescado dormía allí". Ahora las ciénagas están sedimentadas y el uso de nuevas tecnologías como el trasmallo y el chinchorro (que arrasan con todo porque son de ojo muy pequeño) hizo que "el pescado cogiera malicia". "Ya el pescado no encuentra tranquilidad", continúa Aníbal, "porque las mallas no lo dejan descansar".

La catanga que era el río se ha ido vaciando, explica Maryury Mosquera, guardiana representante de Cocomopoca, quien define el Atrato como aquel recipiente tejido en el que suele guardarse el producto de la pesca y las cosechas. Con las orillas ahora volteadas, la vida orillera se ha transformado radicalmente. Ante este panorama los guardianes precisan la tarea de convertirse en "fieras" que, como los quícharos ${ }^{21}$, sostiene Elbys, proveniente del Andágueda, custodien el Atrato para que a través de su vida siga siendo posible florecer en sus orillas.

\section{Seguir el hilo para recomponer la trama}

Seguir el hilo del río se nos presentó como la forma más adecuada de pensar junto con el grupo de Guardianes del Atrato los desafíos que enfrentan. Sin embargo, para poder seguir el hilo y desentrañar algunas de las hebras de la compleja madeja que se ha ido enmarañando a lo largo del tiempo, necesitamos otras herramientas conceptuales y metodológicas.

¿Cómo enfrentarnos a la situación en la que un(os) río(s), que son el eje de la vida en la región, se encuentran en un estado crítico? ¿Cómo imaginar el futuro de la vida mientras el envenenamiento durante tanto tiempo silencioso

20 Lentear es sumergirse en el río con careta para atrapar a los peces con arpón o con las propias manos y a pulmón libre.

21 Refieren la existencia, en las bocas de algunos ríos, de un pez gigante que devora hombres. El quícharo es una "fiera". 
de sustancias tóxicas como el mercurio se está haciendo evidente? ¿Cómo reconocerle derechos al río al mismo tiempo que sus habitantes descubren que el azogue con el que han convivido desde que tienen memoria, cuyo uso se ha disparado con las actividades mineras de enclave extractivo con maquinaria de gran porte y que creían inofensivo, es el mismo mercurio que está acabando con la pesca? ¿Cómo responder al hecho de que en ocasiones la minería tradicional usa azogue, y por tanto también afecta el río, en especial cuando las opciones de ganarse la vida son tan restringidas y, por tanto, la oposición a la minería puede acarrear conflictos dentro las comunidades?

Por tratarse de una intervención que busca hacer frente a daños que el Atrato ha sufrido debido a la acción humana, la sentencia de la Corte que lo declara sujeto de derechos podría interpretarse como un evento que se inscribe en la idea de que la especie humana se ha tornado en una fuerza geológica capaz de transformar el planeta a la misma escala que lo hacen vientos, mareas y volcanes. Así las cosas, la tala indiscriminada, la minería de gran porte y el crecimiento de los monocultivos a orillas del Atrato serían expresiones de esa potencia humana de intervenir en los procesos de formación y reformación planetaria. Un ejemplo de ello puede rastrearse en el testimonio de uno de los guardianes que afirma, pensando en el río, que "hemos contaminado en quince años lo que no contaminamos en cien años”. Al plantear así el problema, los guardianes apuntan a la profunda paradoja que yace en el meollo de este momento histórico -y para algunos geológico— ${ }^{22}$, pues al mismo tiempo que se declara que el ser humano se ha convertido en una fuerza geomorfológica al modo de las placas tectónicas o de los tifones, nos obliga a considerar hasta qué punto toda la vida humana permanece irremediablemente atada a condiciones geológicas y biológicas legadas por la Tierra y los sistemas cósmicos (Clark 2014, 27).

El sueño ilustrado de la completa separación de los rigores de las fuerzas del planeta gracias a la cultura y la economía sufre así un duro golpe. La sociedad occidental vuelve a encontrarse de lleno inmersa en relaciones físicas, químicas y geológicas que no controla (del todo). Al volver a estar expuesta a fuerzas de las que se creía emancipada, la humanidad debe entregarse a ejercicios de imaginación ecopolítica, singulares y locales, que le permitan estar a la altura de las

22 Dependiendo de la causa que se determine en el origen del supuesto nuevo periodo geológico, se han propuesto diversas formas de nombrarlo: Antropoceno, Plantacioceno, Capitaloceno, Faloceno o, incluso, Chthuluceno (Haraway 2015; LaDanta LasCanta 2017; Vince 2014; Zalasiewicz et al. 2008). Consideramos que hablar de Capitaloceno en lugar de Antropoceno permite ver mejor las dinámicas destructivas del sistema capitalista y su continua capacidad de expandirse y generar ruinas, pero a la vez, la posibilidad de vivir en esas mismas ruinas (Tsing 2015). 
nuevas demandas. Por tanto, el espacio acuático en el que consiste la cuenca del Atrato no debe ser entendido como un espacio discreto y autocontenido, sino por el contrario, como el lugar de procesos ecopolíticos que configuran, posiblemente de maneras nuevas e inesperadas, las relaciones que urden los seres que en él habitan.

En ese sentido avanza la sentencia de la Corte Constitucional, al pasar de la noción de derechos bioculturales a la consideración del río como un sujeto de derechos. El primero es un enfoque relacional de los derechos, en el que la vida de las comunidades, en este caso orilleras, no puede separarse del río. Por lo tanto, cualquier daño al río conlleva una vulneración a los derechos de esas comunidades. El segundo implica, creemos, un salto cualitativo, pues ya no estamos hablando de cómo lo que le pase al río le pasa a su gente, y viceversa ("como si fuéramos almas gemelas”, de acuerdo con los guardianes), sino que le da un peso ontológico propio y autónomo al río, que debe ser respetado en sus derechos, independientemente de los humanos que se relacionen con él.

Ante la aseveración de que el mundo contemporáneo precisa de "historias naturales más aventuradas, más experimentales” (Haraway 2016, 2), nos preguntamos si de eso se tratan la Sentencia T-622 del 2016 y la conformación de los Guardianes del Atrato, es decir, de si estamos ante un experimento, una forma de aventurarse en nuevas conversaciones y acciones que abran la posibilidad de desarrollar un "arte de vivir en un planeta dañado” (Haraway 2016, 87). Se trataría esta de una conversación en la que el río no es el convidado de piedra, ni el contexto, ni el paisaje, ni el recurso, sino uno más de los que están sentados a la mesa, un cum-panis, “con quien se vive y se comparte el pan” (Haraway 2008, 17); uno más de los convocados al Parlamento de las Cosas.

Esa historia natural más aventurada y experimental aún está por escribirse a orillas del Atrato. Si bien los guardianes encuentran en el río rasgos que podrían corresponder a los de un sujeto con personalidad propia, encontramos que les es difícil imaginarlo en absoluta autonomía respecto de las vidas humanas que de él dependen. Los daños sufridos por el río lo son en tanto afectan la vida orillera. En esa medida, el peso ontológico que los guardianes le reconocieron al Atrato durante el taller depende de los beneficios o perjuicios que los cambios en las aguas y los cauces suponen para las comunidades humanas. No se trata de una relación meramente instrumental en la que el río es reducido a mero conjunto de recursos a entera disposición de la vida humana, pero tampoco es una relación del todo simétrica. La imaginación ecopolítica aún no ha logrado desligar al río de la estrecha historia que ha tejido junto a quienes moran en sus márgenes. Quizás tal independencia ontológica no sea necesaria para que la 
sentencia encuentre modos de hacerse efectiva en el territorio, pero esto es algo que solo el tiempo podrá decir.

\section{Reflexiones finales}

Los hilos que en la historia han ligado gran parte de las comunidades orilleras del Chocó con sus ríos se vienen tensando peligrosamente en las últimas décadas. El reconocimiento del Atrato como sujeto de derechos está comenzando a reconfigurar el mundo atrateño, abriendo paso a este experimento de imaginación ecopolítica, que muy probablemente requiera de más de una generación para afianzarse. La creación del grupo de Guardianes del Atrato a partir de la interpretación local de la sentencia, por ejemplo, es seña de que esta ya está teniendo efectos a lo largo de la cuenca. Por tanto, creemos importante no limitar la discusión a los aspectos más formalistas de la norma o a los alcances que una iniciativa jurídica como esta pueda llegar a tener, sino comenzar a trazar desde ya las ligazones y los rompimientos que ha propiciado.

En estas páginas hemos querido seguir el hilo de las nuevas conversaciones y encuentros que se han tejido a propósito de la sentencia para no perder de vista el trasfondo del asunto: la violencia que supone la apropiación de recursos en el marco de la fase actual del capitalismo, especialmente en su faceta extractivista, que en el caso del Atrato se expresa ante todo en la minería de oro mecanizada de gran porte y su paquete tecnológico. Es en este sentido que hemos venido hablando de imaginación ecopolítica, pues frente a tal violencia las comunidades no han dejado de buscar alternativas, tal y como prueba la tutela que dio origen a la sentencia.

Creemos que la creación del grupo de Guardianes indica el surgimiento, incierto y tentativo, de un nuevo sujeto colectivo ecopolítico que ha comenzado a anudar ríos y comunidades de maneras inéditas, precisamente porque la sentencia los ha obligado a pensar el río como sujeto de derechos, esto es, como sujeto con peso ontológico propio, algo novedoso para muchos de los orilleros atrateños. En esta medida, no se trata de si el río es verdaderamente un sujeto de derechos, sino de las estrategias, siempre locales y tentativas, mediante las cuales las comunidades, ahora a cargo de la formulación y el cuidado de tales derechos, dan cuerpo y fuerza de ley a la sentencia. Esto conlleva varios desafíos. Entre ellos está el de ligar la diversidad de gentes que tienen algo en común: el ser orilleros, una identidad fundada en la relación con el río. Así, la sentencia permite el 
encuentro de los muchos y distintos pueblos que habitan la cuenca del Atrato. Hombres y mujeres del Alto, Medio y Bajo Atrato conversan sobre lo que es preciso hacer en relación con la restauración del río; distintas organizaciones de base, destinadas desde hace décadas a trabajar por la gente y los ríos chocoanos, se encuentran para definir cuál es el camino que podría conducir a la sanación del río. Indígenas, campesinos mestizos y pueblos negros intentan hablar un mismo lenguaje que, sin desconocer las diversas formas de entenderse con el río, apunte a la reinvención de la vida orillera.

Uno de los asuntos que más ha demandado diálogo y concertación ha sido el de si continuar o no haciendo minería. Aquí hay un desencuentro entre comunidades negras y pueblos indígenas, pues a diferencia de las primeras, los emberas nunca se han definido como un pueblo minero. Aun así, aceptan la posibilidad de defender la minería tradicional que las comunidades negras han practicado durante siglos, aunque no sin renuencia. Este diálogo ilustra cómo, mediante la construcción de un lenguaje compartido, el grupo de Guardianes ha comenzado a reclamar la atención de las entidades del Estado que han desconocido de manera sistemática las exigencias de los pueblos atrateños.

Es necesario tener presente que la declaración del río Atrato como sujeto de derechos no es producto, como en otros casos en el mundo, de la lucha de unas comunidades que entienden al río como un otro ontológicamente simétrico ${ }^{23}$. Por eso, descifrar qué entienden las comunidades orilleras por río como sujeto y cómo concretarlo en la práctica implica unos esfuerzos muy grandes para el grupo de Guardianes. Se trata al menos de cuatro tareas, cada una de una densidad considerable. Primero, ponerse de acuerdo en la diversidad de visiones y comprensiones del mundo de quienes componen este sujeto colectivo que tiene la responsabilidad de representar al río y de entenderlo como un sujeto. Segundo, hacer un proceso de traducción que tienda puentes entre los derechos enunciados en la sentencia (protección, conservación, mantenimiento y restauración), y lo que el grupo de Guardianes y sus comunidades entienden por cada uno de ellos. Tercero, dar a conocer la sentencia y dialogar con las múltiples voces de la vida orillera, en una cuenca extensa y de difícil acceso ${ }^{24}$, donde la declaración del río es el resultado de una "larga historia de lucha del pueblo iwi" (Kothari y Bajpai 2018, 32). viales para el transporte, que se pueden ver interrumpidas por diferentes razones, desde el cierre del tránsito por parte de grupos armados al margen de la ley, hasta por la imposibilidad de su navegación como resultado de la sedimentación y el desvío del cauce debidos a las máquinas de la minería. 
de la Corte Constitucional es ajena a la vida cotidiana de buena parte de sus habitantes. Y cuarto, asegurarse de que la sentencia se cumpla, trabajando con las diferentes dependencias del Estado implicadas, construyendo planes de acción, haciéndoles seguimiento a los compromisos adquiridos y evaluando su nivel de efectividad. Estos esfuerzos requieren recursos que deberían ser suplidos por el Estado, pero que hasta el momento las comunidades han solventado a través de distintas organizaciones del orden civil.

Los hilos que se entrecruzaban en la relación con el río como proveedor de metales preciosos, y que implicaban un trabajo arduo para identificar los depósitos, acceder a ellos con la ayuda de herramientas que durante siglos se mantuvieron sin mayores cambios, o con incorporaciones tecnológicas de pequeña escala, y que se amarraban a formas de organización del territorio y sus habitantes, están mostrando no resistir la presión de las grandes máquinas. Esos hilos se van reventando y desmadejando el territorio: el vínculo con el agua, que ahora debe incorporar al aguasucia, con sus presencias tóxicas y sus vidas ausentes; el vínculo entre las personas y sus organizaciones, y las formas de apropiarse del territorio y lo que este provee; el vínculo entre la minería y las otras actividades económicas, como la agricultura y la pesca, a las que antes complementaba y ahora reemplazó, por mencionar algunas. Esto implica que la relación entre las comunidades y la minería debe volver a atarse, identificando nuevos enlaces y nudos posibles. Eso no podrá hacerse solo con la voluntad de las comunidades del río; requiere profundos cambios en el modelo de desarrollo actual, el cuestionamiento a la misma noción de desarrollo y la forma en que se liga con las instituciones, los marcos normativos, los actores que lo promueven y que se benefician de ellos, tanto los legales como los ilegales (Escobar 2007). El grupo de Guardianes y las organizaciones representadas en él tienen propuestas que no han sido escuchadas ni tenidas en cuenta, y cuya inclusión no es garantizada por la existencia de la sentencia per se. Se trata, en buena parte, de una cuestión de gobernanza del agua (Bocarejo 2018), bastante precaria, desigual y fragmentaria en este caso, ya que no todos los actores (incluidos los no humanos) implicados en su uso, manejo y regulación participan de la misma manera ni con los mismos recursos. El reto consistiría, por tanto, en cómo activar la imaginación ecopolítica en un escenario de relaciones socioeconómicas tan desiguales que determinan un ingreso igualmente desigual al Parlamento de las Cosas. Creemos que el ejemplo del taller arroja una luz sobre cómo podría resolverse esta incertidumbre, si bien nunca de manera perfecta o definitiva.

No queremos cerrar estas consideraciones sin dejar de mencionar lo que, siguiendo a Benjamin, llamaríamos el instante de un peligro $(1973,4)$. Varios de 
los miembros del grupo de Guardianes nos expresaron su incertidumbre frente a la llegada de un nuevo gobierno y el escaso apoyo que hasta ese momento habían recibido de la administración de Juan Manuel Santos. El desinterés de los gobiernos central y departamental frente al trabajo de los Guardianes abre el campo para que el doble peligro de la criminalización y la militarización se imponga sobre su trabajo de representación de los derechos del río, con la excusa de "proteger" precisamente tales derechos. No se trata de temores infundados, pues no sería la primera vez que el Estado colombiano recurra a la persecución de las comunidades locales y sus prácticas bajo la figura de la preservación de recursos y territorios (Lyons 2018). Frente al instante de este peligro, la imaginación ecopolítica del grupo de Guardianes busca el hilo del río en aras de comenzar a urdir nuevas posibilidades para la vida orillera, en las que vidas humanas y no humanas, comunidades y ríos, puedan florecer en medio de los daños, graves aunque quizás no irreparables, que la desmedida búsqueda de riqueza rápida ha dejado en la cuenca del Atrato en forma de aguasucia, tóxicos y ríos sin cauce. Frente al peligro que "amenaza tanto al patrimonio de la tradición como a los que lo reciben” (Benjamin 1973, 4), los Guardianes del Atrato luchan por que ese patrimonio no sea uno de contaminación y despojo, sino uno de florecimiento mutuo, que pueda ser legado a los futuros guardianes del río.

\section{Agradecimientos}

Este trabajo es resultado del proyecto de investigación "Minería en el marco del postconflicto: aportes a la concreción y seguimiento de la Sentencia 622 del 2016 sobre los derechos del río Atrato", financiado por la Oficina de Investigaciones de la Universidad Icesi y dirigido por la profesora Inge Valencia. Se basa en trabajo de campo llevado a cabo durante el 2018 con la colaboración del grupo de Guardianes del Atrato y el Centro de Estudios para la Justicia Social Tierra Digna. Agradecemos a la comunidad del Consejo Comunitario de La Playa, municipio de Lloró. En la Universidad Icesi, agradecemos al profesor Juan Pablo Milanese por la creación del mapa de la cuenca del Atrato, y a la profesora Natalia Rodríguez por su asesoría con los aspectos jurídicos de la sentencia. 


\section{Referencias}

Aguirre, Jorge. 2017. "La democracia líquida: exigencia de la sustentabilidad eco-política”. Araucaria. Revista Iberoamericana de Filosofía, Política y Humanidades 19 (38): 73-96. https://revistascientificas.us.es/index.php/araucaria/article/view/2862

Aprile-Gniset, Jaques. 1993. Poblamiento, hábitats y pueblos del Pacífico. Cali: Ediciones Universidad del Valle.

Benjamin, Walter. 1973. Tesis de filosofía de la historia. Madrid: Taurus.

Bocarejo, Diana. 2018. "Gobernanza del agua: pensar desde las fluctuaciones, los enmarañamientos y políticas del día a día”. Revista de Estudios Sociales 63: 111-118. https://doi. $\operatorname{org} / 10.7440 /$ res63.2018.09

Chakrabarty, Dipesh. 2009. “The Climate of History. Four Theses”. Critical Inquiry 35: 197-222. https://doi.org/10.1086/596640

Clark, Nigel. 2014. "Geo-Politics and the Disaster of the Anthropocene”. The Sociological Review 62 (1): 19-37. https://doi.org/10.1111/1467-954X.12122

Escobar, Arturo. 2007. La invención del tercer mundo: construcción y deconstrucción del desarrollo. Caracas: Fundación Editorial el Perro y la Rana.

Galindo, María Isabel. 2018. "Viviendo con el mar. Inestabilidad litoral y territorios en movimiento en La Barra, Pacífico colombiano”. Revista Colombiana de Antropología 55 (1): 29-57. https://doi.org/10.22380/2539472X.569

Gudynas, Eduardo. 2014. Derechos de la naturaleza. Ética biocéntrica y políticas ambientales. Lima: PDTG; redGe; CooperAcción; Claes.

Guimarães, Roberto. 1989. "La ecopolítica en el desarrollo del Brasil”. Revista de la Cepal 38: 89-104.

Haraway, Donna. 2008. When Species Meet. Minneapolis; Londres: University of Minnesota Press.

-. 2015. “Anthropocene, Capitalocene, Plantationocene, Chthulucene: Making Kin”. Environmental Humanities 6: 159-165. https://doi.org/10.1215/22011919-3615934

-. 2016. Staying with the Trouble. Making Kin in the Chthulucene. Durham; Londres: Duke University Press.

Isacsson, Sven-Erik. 1975. "Biografía atrateña. La formación de un topónimo indígena bajo el impacto español (Chocó, Colombia)”. Indiana 3: 93-109. http://dx.doi.org/10.18441/ind. v3i0.93-110

Kothari, Ashish y Shrishtee Bajpai. 2018. “¿Somos el río, o en el río somos?”. Ecología Política 55: 32-40. https://www.ecologiapolitica.info/?p=10746

LaDanta LasCanta. 2017. "El Faloceno: redefinir el Antropoceno desde una mirada ecofeminista”. Ecología Política 53: 26-33. https://www.ecologiapolitica.info/?p=9705

Lahiri-Dutt, Kuntala. 2019. “Imaginando los ríos”. Revista Colombiana de Antropología 55 (1): 153-166. https://doi.org/10.22380/2539472X.574 
Latour, Bruno. 2007. Nunca fuimos modernos. Ensayo de antropología simétrica. Madrid: Siglo XXI.

Leal, Claudia. 2016. "Libertad en la selva. La formación de un campesinado negro en el Pacífico colombiano, 1850-1930”. Revista CS 20: 15-36. https://doi.org/10.18046/recs.i20.1861

Losonczy, Anne-Marie. 2006. La trama interétnica. Ritual, sociedad y figuras de intercambio entre los grupos negros y embera del Chocó. Bogotá: ICANH; IFEA.

Lyons, Kristina. 2018. "Rivers Have Memory: Community Recovery of a Watershed in Times of Perpetual Conflict and Transition”. Ponencia presentada en el Congreso de la American Anthropology Association, San Jose, California, 14-17 de noviembre.

Mcpherson, Elizabeth y Felipe Clavijo Ospina. 2018. "The Pluralism of River Rights in Aotearoa, New Zealand and Colombia”. Journal of Water Law 25 (6): 283-293.

Motta, Nancy. 2005. Gramática ritual. Territorio, poblamiento e identidad afropacífica. Cali: Universidad del Valle.

Oslender, Ulrich. 2002. “The Logic of the River’: A Spatial Approach to Ethnic-Territorial Mobilization in the Colombian Pacific Region”. Journal of Latin American Anthropology 7 (2): 86-117. https://doi.org/10.1525/jlca.2002.7.2.86

-. 2008. Comunidades negras y espacio en el Pacífico colombiano. Hacia un giro geográfico en el estudio de los movimientos sociales. Bogotá: Universidad Colegio Mayor de Cundinamarca; ICANH; Universidad del Cauca.

Quiceno, Natalia. 2016. Vivir sabroso. Luchas y movimientos afroatrateños en Bojayá, Chocó, Colombia. Bogotá: Editorial Universidad del Rosario.

Serres, Michel. 2004. El contrato natural. Valencia: Pre-Textos.

Stutzin, Godofredo. 1984. "Un imperativo ecológico: reconocer los derechos de la naturaleza”. Ambiente y Desarrollo 1 (1): 97-114.

Szerszynski, Bronislaw. 2012. "The End of the End of Nature: The Anthropocene and the Fate of the Human”. The Oxford Literary Review 34 (2): 165-184. www.jstor.org/stable/44030881

Tierra Digna. 2016. La minería en Chocó en clave de derechos. Investigación y propuestas para convertir la crisis socio-ambiental en paz y justicia territorial. Bogotá: Tierra Digna.

Tsing Lowenhaupt, Anna. 2015. The Mushroom at the End of the World. On the Possibility of Life in Capitalist Ruins. Princeton; Oxford: Princeton University Press.

Valencia, Inge y Sabina Rasmussen. 2018. Entre las rentas ilegales, el recrudecimiento de la violencia y la implementación escasa de los programas de desarrollo con enfoque territorial. Bogotá: Fescol.

Vince, Gaia. 2014. Adventures in the Anthropocene. A Journey to the Heart of the Planet We Made. Minneapolis: Milkweed Editions.

Wade, Peter. 2006. "Etnicidad, multiculturalismo, y políticas sociales en Latinoamérica: poblaciones afrolatinas (e indígenas)”. Tabula Rasa 4: 59-81. http://www.scielo.org.co/pdf/ tara/n4/n4a04.pdf 
West, Robert. 2000. Las tierras bajas del Pacífico colombiano. Bogotá: ICANH.

Zalasiewicz, Jan, Mark Williams, Alan G. Smith, Tiffany L. Barry, Angela L. Coe, Paul R. Bown, Patrick Brenchley, David Cantrill, Andrew Gale, Philip Gibbard, F. John Gregory, Mark W. Hounslow, Andrew C. Kerr, Paul Pearson, Robert Knox, John H. Powell, Colin Neil Waters, John E. A. Marshall, Michael Oates, Peter Rawson y Philip Stone. 2008. “Are We Now Living in the Anthropocene?”. GSA Today 18 (2): 4-8. https://doi. org/10.1130/GSAT01802A.1 